\title{
Augmenting the Stability of OB Dump by Using Fly Ash: A Geo Technical Approach to Sustainably Manage OB Dump at Jharia Coalfield, India
}

\author{
ANUP KUMAR GUPTA ${ }^{1 *}$ and BISWAJIT PAUL ${ }^{2}$ \\ ${ }^{1}$ Research Scholar, ${ }^{2}$ Associate Professor \\ Department of Environmental Science \& Engineering, Indian School of Mines, Dhanbad, India. \\ http://dx.doi.org/10.12944/CWE.11.1.25
}

(Received: December 08, 2015; Accepted: January 19, 2016)

\begin{abstract}
This paper is mainly focused over the possible utilization of fly ash along with OB dump to enhance the stability of $\mathrm{OB}$ dump and thus provide a sustainable approach for better waste management of both these materials simultaneously. Instability of coal mine overburden (OB) dumps is an important problem in most of the coal mines like Jharia coalfields in India. This is mainly occurring due to sliding nature of the rock material, lack of vegetation etc. Numbers of Environmental and health issues are associated with these unstable OB dumps. As it may easily flow with running water can contaminate the nearby water resource as well as carbonaceous content of the dump causes air pollution due to simultaneous combustion. On the other hand management of coal ash that is produced from thermal plants is also an important task. Dumping of fly ash in open may cause number of environmental problems. Various geotechnical and physical parameters such as particle size analysis, specific gravity, density, and friction angle/cohesion test have been performed to check the stability of OB dump and to analyze impacts of fly ash utilization to stabilize the OB dump.
\end{abstract}

Key words: OB dump instability, fly ash, shear strength, sustainable approach.

\section{INTRODUCTION}

India is third largest coal producing country in world after China and USA, where power sector is dominated by coal based thermal power plants ${ }^{1}$. Coal mining in India is performed with both the mining techniques i.e., underground and opencast mining. Opencast mining is the chief mining practice in our country with about eighty percent of total coal production. Opencast mining includes rupture the upper layer of rocks with blasting, drilling to excavate the valuable mineral as coal is buried in deep under thick layers of rock. In this way huge amount of waste rock in form of $\mathrm{OB}$ is generated (Table.1) that is dumped to the nearby areas and can be easily seen as hilly structure (Fig.1) near Jharia coalfield. Production of $\mathrm{OB}$ material is directly depends on the stripping ratio i.e., amount of $\mathrm{OB}$ in ton is required to excavate per ton of coal. The average stripping ratio during last three decades was $1.97 \mathrm{~m}: 3 /$ ton $^{2}$. Probably most of these OB materials are dumped to the nearby areas thus huge hilly structure can be easily seen in Jharia coalfields and nearby areas. Instability of OB dump is a major problem in Jharia coalfield and a big threat to the nearby working people. ${ }^{10} \mathrm{Kainthola}$ et al. (2011) reported such type of OB dump instability in Western Coalfields Ltd. It was about $75 \mathrm{~m}$ in height and with $43^{\circ}$ slope angle and found slipped ahead by $18 \mathrm{~m}$. Another incidence of the failure occurred at New Majri Opencast coal mine of WCL, a $150 \mathrm{~m}$ long failure occurred in the strike direction of the $60 \mathrm{~m}$ high pit slope. Geotechnical studies carried out indicated the cohesion and angle of internal friction values for the soil were $48 \mathrm{kPa}$ and $23<$ " respectively. There is a stern threat to the existing ecosystem due to mining operations mainly due to opencast mining where huge amount of waste rock or overburden material is produced 
and dumped on site for a long period. These OB dumps are quite adverse for growth of vegetation due to lack of valuable nutrients ${ }^{3}$.

Production of such a huge amount of $\mathrm{OB}$ dump material from Jharia coalfield is adversely affects the natural land property and environment as well ${ }^{4}$.

\section{Instability problems of $\mathrm{OB}$ dumps}

Due to continuous increase in dump heights there is a possible threat of their stability and related problems. Thus study and monitoring OB dumps, their stability is an important issue in mining sector. Various incidents related to instability of OB dumps have already been reported earlier due to dump slides and failures that adversely affect the nearby residing population. A rock slope may become unstable and fail due to discontinuities in rock strata and lack of cohesiveness. Stability is hindered due to clay band between the two rock bands in mine spoil or OB dump.

Shear strength of a soil is thus the sum of the cohesive and frictional contributions. Higher is the cohesion value, more stable will be the slope thus it is important to evaluate the cohesive properties of the dump material to promote their shear strength which can be achieve with direct shear test.

Stability of the slope is depending on the shear strength of the material existing along such surface and their orientation related to the slope. Briefly the factor on which stability of any dump is depends are: texture of the particles, specific gravity, state of the packing or compaction, degree of saturation etc ${ }^{5,6}$. Shear strength properties are product of cohesiveness of the particles $(C)$ and friction angle $(\varnothing)$ that is present along joint surface that is depends on the mechanical and functional characteristics of the surface. OB dump materials where sandstone is the main composite material has very less value for coefficient of internal friction (0.51), angle of internal friction (26.6), cohesion (28) thus have tendency to be easily unsterilized ${ }^{7}$. Bonding or joints within the strata can creates failure planes that involve a combination of joint sets that provide a cross over surface stability.

Geometrical properties of the slope are the most important factor which affects its stability. Some of the key features of slope design parameters that affect the geometric properties are height of the bench, slope angle and the total area of failure surface. Slope stability is thus depends on height as the height increases stability decreases. The curvature of the slope has deep effect on the instability, thus convex part of the slopes should be avoided in the slope design. Displacement of rock strata is dominantly found near the crest of the dump due to maximum instability at that point ${ }^{8}$ thus any investigation that is related with dump instability should be performed from crest of the dump slope. Revegetation is one of the most suitable technique used to stabilize dump slopes. Stability investigation of a dump slope of Munidih mine in Dhanbad revealed the cohesion and friction angle values of the $30 \mathrm{~m}$ high, $35.5<$ " angle dump as $0.6 \mathrm{~kg} / \mathrm{cm}^{2}$ and
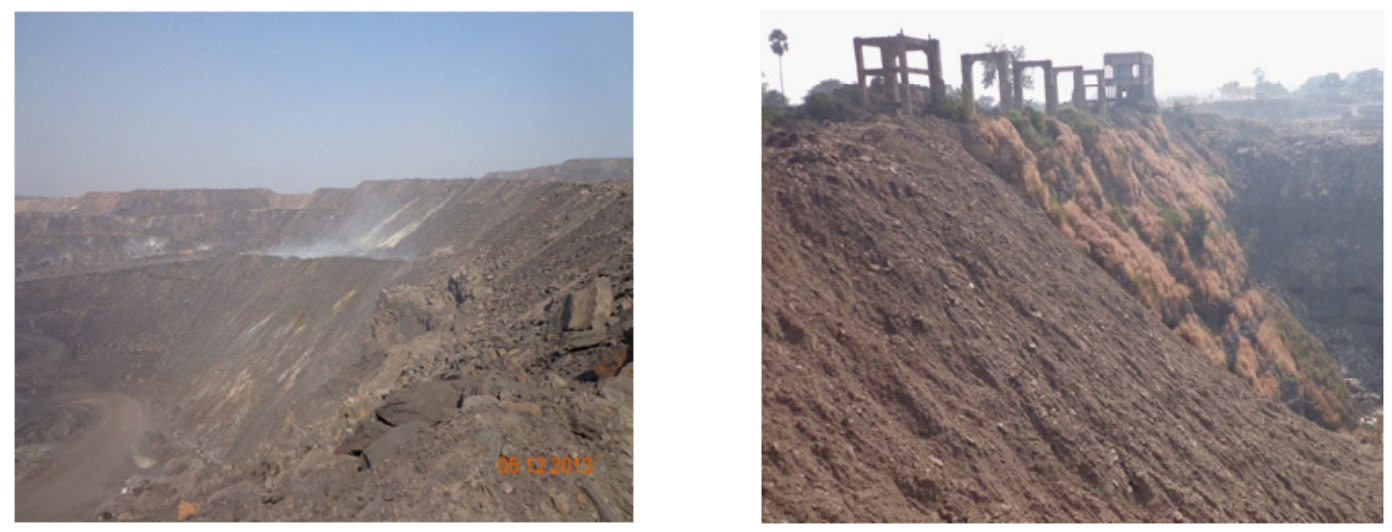

Fig. 1: OB dumping near Kusunda Opencast mines 
31.5․ Stability of waste dumps is very crucial due to the non-availability of land, weak rock conditions as well as heavy rains ${ }^{9}$.

\section{Environmental implication of fly ash}

Thermal power plant generates huge amount of fly ash with the combustion of coal which becomes a severe environmental issue in India. Thermal power plants are greatly facing problem related to management of fly ash. Open dumping of fly ash can deteriorate the groundwater quality by runoff as well as atmospheric pollution. Thus this is very clear that open dumping of fly ash is fatal to the environment in different aspects. Fly ash contains major elements like Silica, Aluminum and Iron with significant amount of Calcium, Magnesium, Potassium, Phosphorous and Sulphur ${ }^{10,11}$. Disposal of fly ash is mainly performed in ash pond by collecting it in the form of wet slurry ${ }^{12}$ which is reasonable for water pollution to the nearby water resource or ground water pollution by leaching to the underground.

\section{Study Area}

OB sample was collected from three different opencast mines of jharia coalfields namely
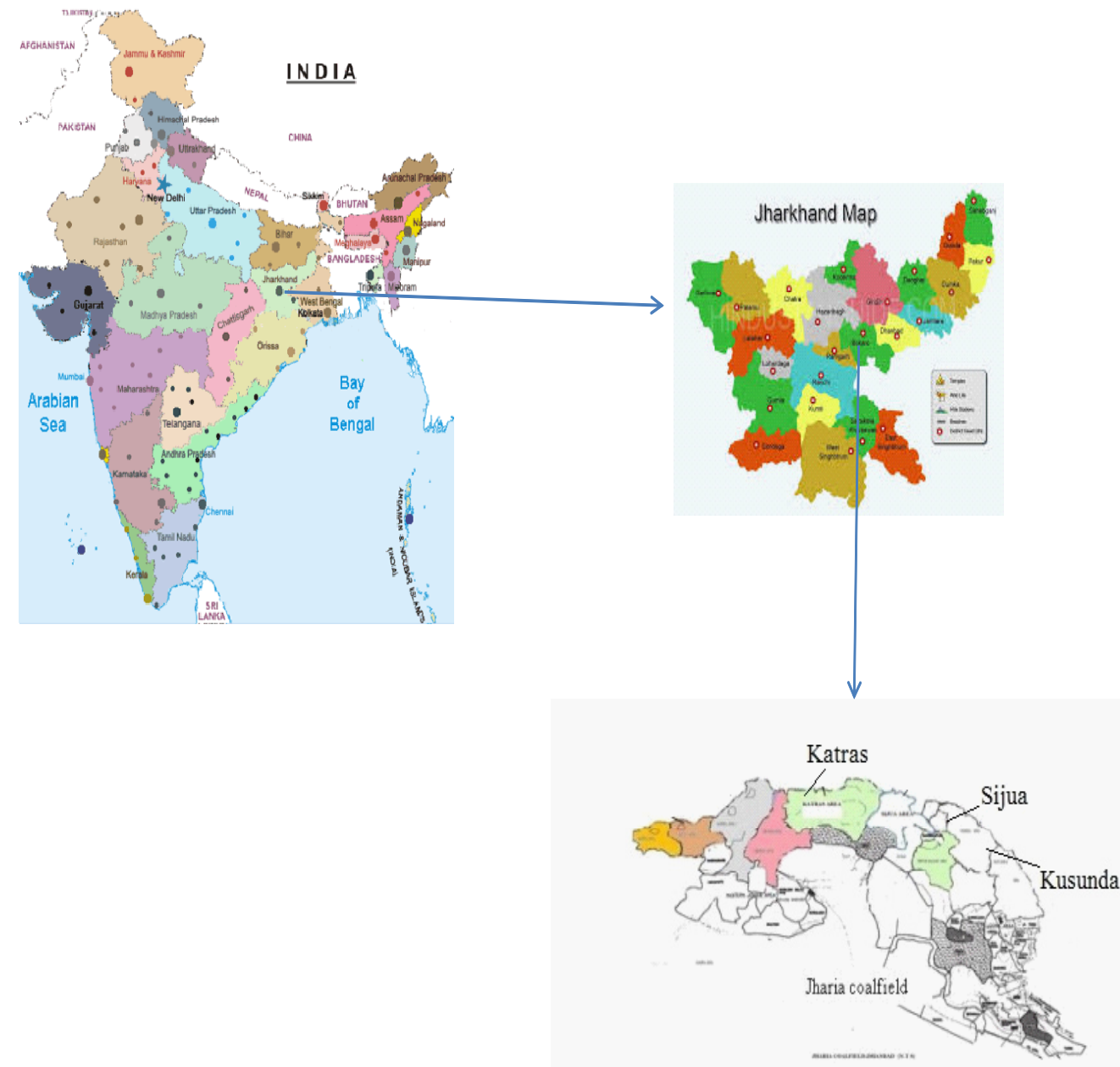

Fig. 2: Study Area Map 
Kusunda, Sijua and PB area (Fig.2) designated as OB1, OB2 and OB3. Sample was collected as naturally crushed $\mathrm{OB}$ material from bottom of the dumps. It was packed in air tight plastic bags and taken to the departmental laboratory for further treatment. Sample was then processed (sieved, screened and washed) for further physical and geotechnical test to evaluate the stability status of the material.

\section{METHODOLOGY}

Collected samples were crushed, sieved and washed for further analysis. Physical and geotechnical properties such as particle size analysis, bulk density, specific gravity; dry density, shear test has been analyzed as per Indian standards ${ }^{13}$.

\section{Parameters studied}

Stability of the OB which is mainly made of sand stone and other soil types depends on number

Table 1: OB production in Jharia coalfield, A Gupta \& B Paul, 2015)

\begin{tabular}{lll}
\hline SI.No & Area & $\begin{array}{l}\text { OB-Production in } \mathrm{M}^{3} \\
\text { from 2009-2013 }\end{array}$ \\
\hline 1 & Kusunda & 58634339 \\
2 & Katras & 43230604 \\
3 & Bastacolla & 27552772 \\
4 & Lodna & 1835336 \\
5 & Sijua & 37035002 \\
6 & PB Area & 1745984 \\
7 & EJ Area & 20453619 \\
8 & Barora & 22623427 \\
9 & Govindpur & 10620235 \\
\hline
\end{tabular}

Table 2: Grain size distribution

\begin{tabular}{lccc}
\hline & OB1 & OB2 & OB3 \\
\hline $\mathrm{D}_{10}$ & 2.8 & 3 & 3.1 \\
$\mathrm{D}_{60}$ & 15.8 & 15.2 & 19.4 \\
$\mathrm{D}_{30}$ & 7.8 & 7 & 8.1 \\
$\begin{array}{l}\text { Coefficient of } \\
\text { uniformity }\left(\mathrm{C}_{\mathrm{u}}\right)\end{array}$ & 6.14 & 7 & 6.6 \\
$\begin{array}{l}\text { Coefficient of } \\
\text { curvature }\left(\mathrm{C}_{\mathrm{C}}\right)\end{array}$ & 3.2 & 2.7 & 3.4 \\
\hline
\end{tabular}

of physical and geotechnical parameters such as grain size, bulk density, specific gravity and shear strength. All these parameters have been analyzed as per Indian standards.

Bulk density and specific gravity of $\mathrm{OB}$ along with river sand was analyzed by density bottles as per IS: 2720 (Part 3/Sec 1) - 1980.

Grain size analysis was performed with sieve shaker with different mesh sizes as per Indian standard 2720 (Part IV)-1985. The sieves were arranged on top of one another such that the coarsest one was at the top and the finest one at the bottom. Oven dried soil sample $(1 \mathrm{~kg})$ was taken and placed on the coarsest sieve. The entire assembly of sieves was placed on the sieve shaker and shaken for about $10 \mathrm{~min}$. The material retained on each sieve was recorded in a tabular format and the cumulative percentage retained was calculated (Table.1). The cumulative percentage of fines was also calculated and the graph between percentage of fines and grain size was plotted (Fig.4).

Direct shear test was performed with direct shear apparatus. The dimensions of the shear box were measured and the mass of the sample to be tested was determined. The required mass of sample was taken in a tray and water added to it at its optimum moisture content. It was then thoroughly mixed. The shear box was $s$ then assembled and sample was transferred to the shear box in three layers. With the top plates fixed on the shear box, it was then transferred to the loading frame. The weights were then attached to the loading frame and the dial gauges set to zero. The machine was started and the proving ring readings were taken up to failure

Table 3: Cohesion and angle of internal friction

\begin{tabular}{lcc}
\hline Sample & $\begin{array}{c}\text { Cohesion } \\
\left(\mathbf{k g} / \mathbf{c m}^{2}\right)\end{array}$ & $\begin{array}{c}\text { Angle of } \\
\text { friction }\left(^{\mathbf{0}}\right)\end{array}$ \\
\hline OB1 & 0.0190 & 31 \\
OB2 & 0.0198 & 31.8 \\
OB3 & 0.0285 & 35 \\
OB+ fly ash 10\% & 0.030 & 30 \\
OB+ fly ash 20\% & 0.0623 & 28 \\
OB + fly ash 30\% & 0.0321 & 30 \\
\hline
\end{tabular}


of the sample. The test was repeated for different weights (normal stress) and the observations were recorded. A graph between normal stress and shear stress was plotted (Fig.5) to calculate the stability of the material.

\section{RESULT AND DISCUSSION}

Bulk density of the OB material was found in the range of 1.09 to 1.24 which while it was enhanced up to 1.3 with fly ash utilization in the proportion of $20 \%$. Specific gravity of OB was found as 2.09 to 2.46

\section{SG \& BD}

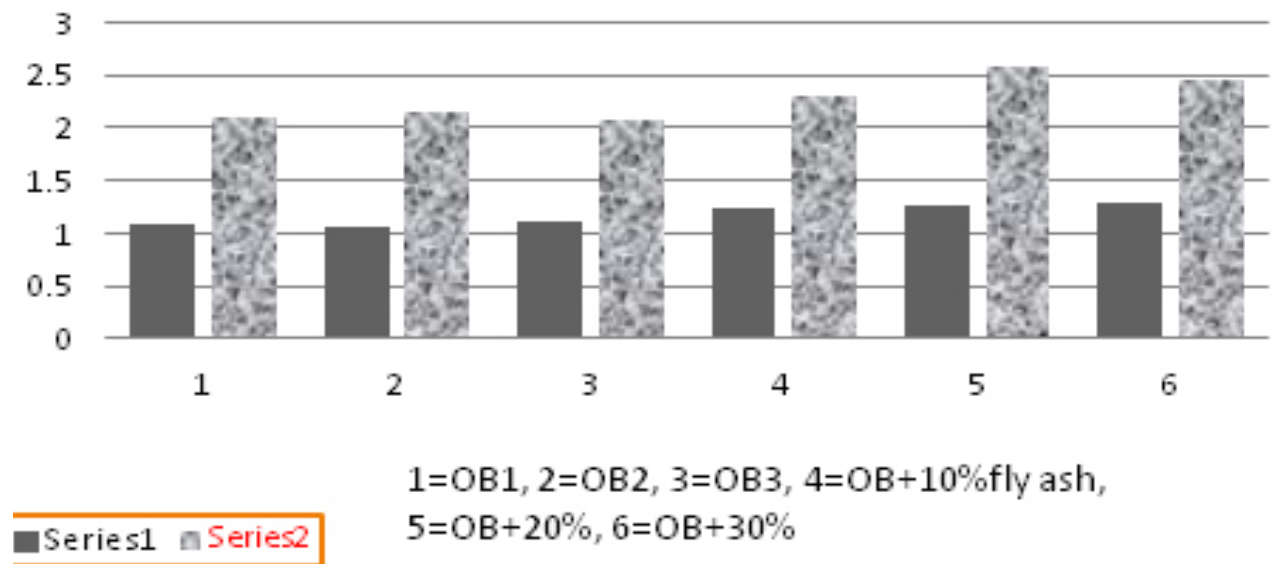

Fig. 3: Specific gravity and Bulk density

\section{OB 1}

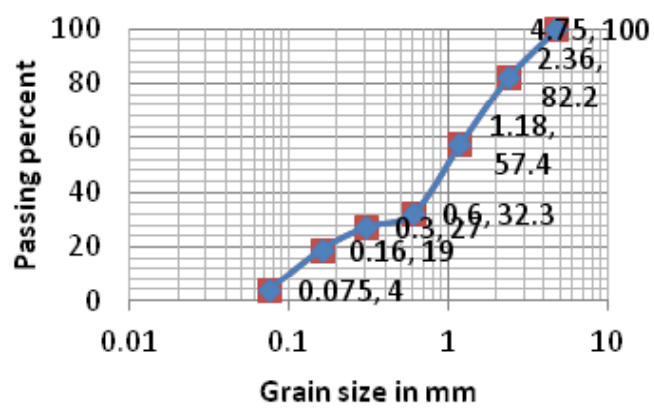

OB 3

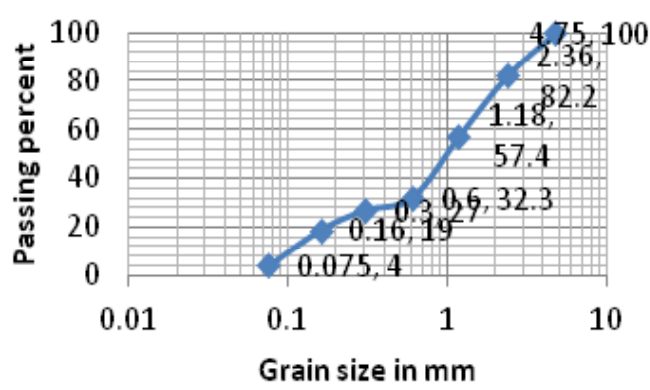

OB 2

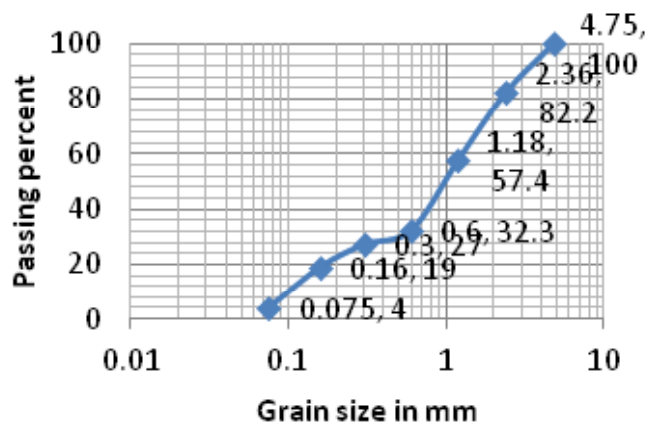

$\mathrm{OB}+$ fly ash

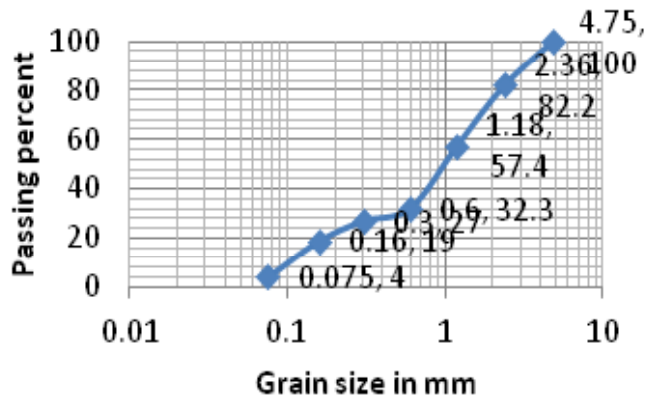

Fig. 4: Graphical representation of grain size distribution 
and with $20 \%$ fly as utilization the value increased up to 2.57 (Fig.3).

Grain size distribution analysis shows that percentage of sand and silt is dominated while clay is negligible with a slight proportion of gravel. Coefficient of curvature and uniformity constant was calculated. Value for $\mathrm{C}_{\mathrm{u}}$ was found in the range of 6 to 7 and $\mathrm{C}_{\mathrm{c}}$ was found as 2.7 to 3.4 as per standard both the values are found as well graded to slightly

\section{OB 1}

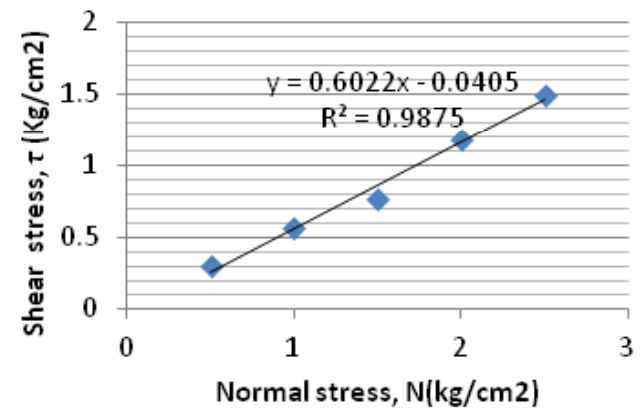

OB3

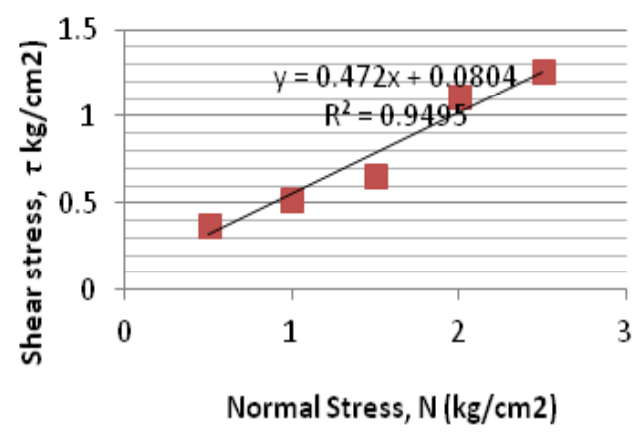

\section{OB + fly ash $\mathbf{2 0 \%}$}

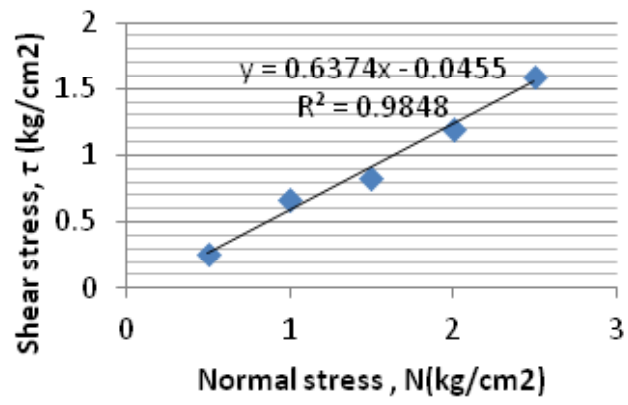

well graded sample. From the graph (Fig. 4) percent of sand silt and clay was calculated and result shows that in all the three samples proportion of sand is dominated with a value between $65-70 \%$. Due to presence of higher sand particles cohesion reduces that ultimately reasonable for easily instability of the dump on the other hand with the addition of fly ash to the OB sample cohesion between particles increases that ultimately reasonable for good packaging and bonding thus provides extra stability to the slope.

OB 2

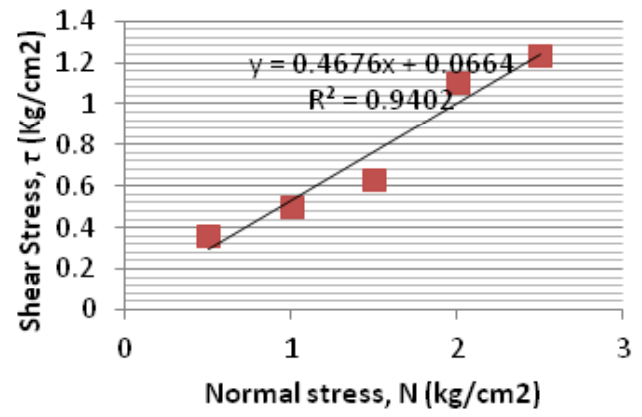

OB $+10 \%$

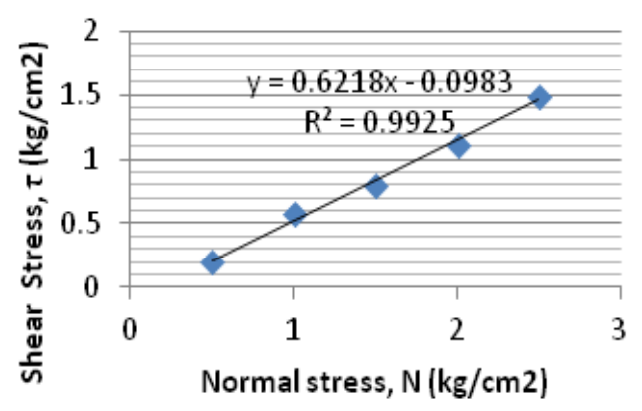

\section{$\mathrm{OB} 1+30 \%$ fly ash}

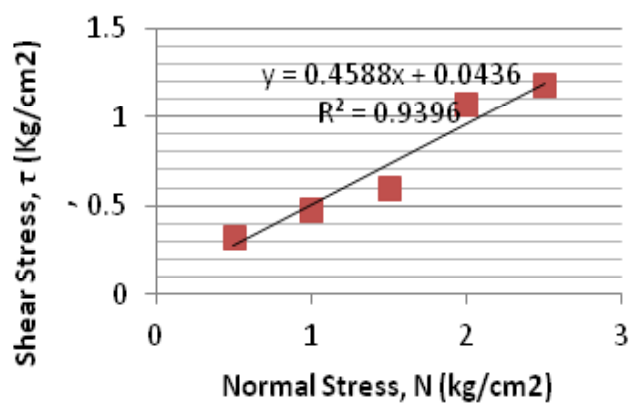

Fig. 5: Shear strength properties of $O B$ and $O B$ with fly ash 
Results of direct shear test shows that the strength properties of $\mathrm{OB}$ are smoothly changed with fly ash. From the graph (Fig.5) it is very clear that $R$ value for OB samples i.e., OB1 OB2 and OB3 were found as $0.987,0.984$, and 0.989 which is good enough but as we mixed fly ash to these samples the values were changed with much more cohesion of the particles and reduced friction angle with about ten to twenty percent. Further addition of fly ash reduces the strength properties ( $R$ value) that indicates reduction in the cohesion and ultimately disturbed the friction angle thus it can be concluded that addition of fly ash with $\mathrm{OB}$ in a limited proportion (10-20\%) can provide good strength value with OB in proportion of $10-20 \%$ is beneficial and may enhance the stability of OB dump.

Disposal of mine waste rock of $O B$ is one of the crucial issues of waste management in most of the mining industries in India and worldwide. This paper is based on a sustainable waste management program where two different types of waste i.e., fly ash and $\mathrm{OB}$ simultaneously used to overcome a major task of instability of OB dump. Jharia coalfields which is the one of the important coal producing regions in India is facing a problem related to $O B$ dump, their disposal and management. On the other hand fly ash disposal is another issue that affects the environment adversely.

Due to lack of any specified waste management plan OB material in Jharia coalfield and other mining areas is dumped improperly and causes various environmental problems like atmospheric pollution due to simultaneous combustion of carbonaceous elements present in the dump and water pollution due to leaching and runoff of metallic concentration to the ground water and nearby water resource. OB dump in coal mine areas are of key interest due to their possible failure and adverse impacts over environment. Ecorestroation with the help of planting tree and plants over OB dump is one of the possible options to provide more stability to the dump on the other hand as per geotechnical and by improving mechanical properties of the material we may stabilize the dump ${ }^{14}$. Fly ash which is another waste indirectly related to coal is a major problem regarding their dumping. Fly ash which is generally dumped to the open environment may cause severe environmental problems due to presence of higher metallic concentration like $\mathrm{Fe}, \mathrm{Sn}, \mathrm{Cd} \mathrm{etc}^{15}$ Thus this is quite suitable and sustainable method for better waste management of fly ash to stabilize the $\mathrm{OB}$ dump.

\section{CONCLUSIONS}

From the above assessment this is quite clear that fly ash shown their valuable impacts over the stability aspects of the OB material at a certain limit. With about 10 to 20 percent positive results were found but as the proportion of fly ash added more and more again mechanical properties deflects negatively and ultimately strength of the material. Angle of friction was calculated between $30^{\circ}-35^{\circ}$ it reduced below $30^{\circ}$ with the addition of 10 and $20 \%$ of fly ash. Thus the angle of friction reduced and ultimately much better cohesion between the particles has been developed. But further addition of fly ash again weakened the stability by disturbing the cohesion and friction angle (Table.3).

Initially slope angle decreases from $32^{\circ}$ to $27^{\circ}$ by adding $10 \%-20 \%$ of fly ash possibly due to inadequate packing of voids between OB particles by the finer sized fly ash particles. Thus ultimately value for angle of slope increased and cohesion decreased. Further increment of fly ash i.e. at $30 \%$, packing of the voids would become more compact as they reduce the void ratio. This would lead to the increase in slope angle obtained with OB $+30 \%$ fly ash from $26 \stackrel{\circ}{\circ}$ to $28^{\circ}$. However, there was no significant change in slope angle with addition of fly ash vis-à-vis OB. Conclusion of this work shows that utilization of fly ash with OB can provide a better stability to the dump as well as a composite waste management plan for the mining industry.

\section{ACKNOWLEDGEMENT}

Authors are like to acknowledge our HOD, department of ESE, Indian School of Mines Dhanbad for their valuable support to complete this paper. We also convey our thanks to MHRD for funding our work and completer this paper. We like to acknowledge our lab mates for their valuable help. 


\section{REFERENCES}

1. Gupta A, Paul, B., Ecorestoration of Coal Mine Overburden Dump to Prevent Environmental Degradation: A Review, Research Journal of Environmental Sciences, 2015 ISSN 18193412 / DOI: 10.3923/rjes (2015).

2. Yaseen S., Pal A., Singh S.,Dar I.S, A Study of Physico-Chemical Characteristics of Overburden Dump Materials from Selected Coal Mining Areas of Raniganj Coal Fields, Jharkhand, India, Global Journal of Science Frontier Research Enviornment \& Earth Sciences, Vol. 12 (1) 1.0 (2012)

3. Singh A.N., Raghubanshi A.S., Singh J.S., Plantations as a tool for mine spoil restoration. Current Science 82: 1436-1441(2002)

4. Rai A.K., Paul B., Singh G., A study on the Bulk density and its effect on the growth of selected grasses in coal mine overburden dumps, Jharkhand, India, International Journal of Environmental Sciences, 1(4); (2010).

5. Hawley, P.M., Site Selection, Characterization, and Assessment; In: W.A. Hustrulid, M.K. McCarter and D.J.A. van Zyl (Editors), Slope Stability in Surface Mining: Society for Mining, Metallurgy, and Exploration, Inc (SME). Littleton, pp. 267-274 (2001).

6. Holtz, R.D. and Kovacs, W.D., An Introduction to Geotechnical Engineering: Civil Engineering and Engineering Mechanics Series, Pearson Education Taiwan Ldt., pp.733 (2003)

7. Jaeger J.C., Cook N.G.W, Fundamentals of Rock Mechanics. Chapman \& Hall, Wiley, New York, 585 pp (1976)

8. Chaulya, S.K., Singh, R.S., Chakraborty, M.K., Dhar, B.B "Numerical Modelling of Biostabilisation for a Coal Mine Overburden Dump Slope”, Ecological Modelling, Elsevier Science Press, London, pp: 5-12., (1999)

9. Kainthola, A., Verma, D., Gupte, S., Singh, T.N., "A Coal Mine Dump Stability Analysis: Case Study", Geomaterials, London, pp: 3-13 (2011)
10. Ivanova T.S., Panov Z., Blazev K. and Paneva V.Z., Investigation of fly ash heavy metals content and physicochemical properties from Thermal Power Plant, Republic of Macedonia. International Journal of Engineering Science and Technology. 3(12): 8219-8225 (2011).

11. Aswar W. R., Fly ash disposal and utilization: National scenario. International Conference on Fly ash Disposal and Utilization, New Delhi, India. 80 -86 (2001).

12. Singh R., Singh R.K., Gupta N.C. and Guha B.K., Assessment of heavy metals in fly ash and Groundwater - A case study of NTPC Badarpur Thermal Power Plant, Delhi, India. Pollution Research. 29(4): 685-689 (2010).

13. I.S: 2720 (Part III/Section 2): Indian standard for determination of specific gravity (fine, medium and coarse grained soil)", Bureau of Indian Standards Publications, New Delhi. (1980)

14. A.K. and Paul, B., A review on utilisation of coal mine overburden dump waste as underground mine filling material: a sustainable approach of mining, Int. J. Mining and Mineral Engineering, 6(2): pp.172-186 (2015).

15. Dhadse S, Kumrari P, Bhagia L J., Fly ash characterization utilization and Government initiatives in India- A Review, Journal of Scientific and industrial research, 67: pp. 1118 (2008)

16. Kanchan S.,Kumar V., Yadav K.K., Gupta N, Arya S., and Sharma S., Effect of Fly Ash Disposal on Ground Water Quality near Parichha Thermal Power Plant, Jhansi: A Case Study, Current World Environment, 10(2), 572-580 (2015)

17. Tripathi N..,Singh. R.S., Swadesh K., Chaulya, Dump Stability and Soil Fertility of a Coal Mine Spoil in Indian Dry Tropical Environment: A Long-Term Study, Environmental Management 50: 695-706 DOI 10.1007/ s00267-012-9908-4 (2012). 